\title{
On the Signatures of Equatorial and Extratropical Wave Forcing in Tropical Tropopause Layer Temperatures
}

\author{
KEVIN M. GRISE \\ Lamont-Doherty Earth Observatory, Columbia University, Palisades, New York \\ DAVID W. J. THOMPSON \\ Department of Atmospheric Science, Colorado State University, Fort Collins, Colorado
}

(Manuscript received 11 June 2012, in final form 18 November 2012)

\begin{abstract}
Temperatures in the tropical tropopause layer (TTL) play an important role in stratosphere-troposphere exchange and in the formation and maintenance of thin cirrus clouds. Many previous studies have examined the contributions of extratropical and equatorial waves to the TTL using coarse-vertical-resolution satellite and reanalysis data. In this study, the authors provide new insight into the role of extratropical and equatorial waves in the TTL using high-vertical-resolution GPS radio occultation data.

The results examine the influence of four different wave forcings on the TTL: extratropical waves that propagate vertically into the stratosphere, extratropical waves that propagate meridionally into the subtropical stratosphere, extratropical waves that propagate meridionally into the subtropical troposphere, and the equatorial planetary waves. The vertically and meridionally propagating extratropical stratospheric waves are associated with deep, zonally symmetric temperature anomalies that extend and amplify with height throughout the lower-to-middle tropical stratosphere. In contrast, the extratropical tropospheric waves and the equatorial planetary waves are associated with tropical temperature anomalies that are confined below $20-\mathrm{km}$ altitude. The equatorial planetary waves dominate the zonally asymmetric component of the TTL temperature field, and both the equatorial planetary waves and the extratropical tropospheric waves are linked to large temperature variability in a 1-2-km-deep layer near the tropical tropopause. The fine vertical scale of the TTL temperature features associated with the equatorial planetary waves and the extratropical tropospheric waves is only readily apparent in high-vertical-resolution data.
\end{abstract}

\section{Introduction}

The tropical tropopause is a key interface in the climate system and plays a principal role in stratospheretroposphere exchange. Temperatures near the tropical tropopause largely govern water vapor concentrations in the lower stratosphere (e.g., Brewer 1949; Mote et al. 1996; Fueglistaler et al. 2009) and contribute to the formation and maintenance of thin cirrus clouds (e.g., Jensen et al. 1996; Massie et al. 2002). In the tropical troposphere, temperatures are determined primarily by latent heating, thermally driven vertical motion, and radiative cooling. In the tropical stratosphere,

Corresponding author address: Kevin M. Grise, LamontDoherty Earth Observatory, Columbia University, P.O. Box 1000, 61 Route 9W, Palisades, NY 10964-8000.

E-mail:kgrise@ldeo.columbia.edu temperatures are determined primarily by mechanically driven vertical motion (due to wave breaking at stratospheric levels) and radiative cooling. But within the approximately $5-\mathrm{km}$-deep layer surrounding the tropical tropopause [the so-called tropical tropopause layer (TTL)], temperatures reflect the combined influences of all of these processes (e.g., Highwood and Hoskins 1998; Gettelman and Forster 2002; Fueglistaler et al. 2009).

Zonal asymmetries in the TTL temperature field are predominantly linked to the quasi-stationary planetary wave pattern in the tropical troposphere (Highwood and Hoskins 1998; Fueglistaler et al. 2009). These equatorial planetary waves reflect the equatorial Rossby and Kelvin wave responses to the climatological-mean distribution of latent heating from deep convection in the tropics (Dima et al. 2005; Dima and Wallace 2007). The observed equatorial planetary waves strongly 
resemble the idealized model response to a localized midtropospheric heat source centered on the equator over the western Pacific Ocean (Gill 1980; Highwood and Hoskins 1998). The waves exhibit a first baroclinic mode structure in the tropical troposphere and become evanescent at stratospheric levels (e.g., Fueglistaler et al. 2009).

The annual cycle in the TTL temperature field is predominantly linked to the annual cycle in mechanically driven upwelling. Temperatures near the tropical tropopause exhibit a pronounced annual cycle with the coldest temperatures during Northern Hemisphere winter (Reed and Vlcek 1969). Because of the long radiative time scales in the tropical tropopause region, changes in vertical velocity are capable of producing large changes in temperatures, particularly on seasonal time scales (Randel et al. 2002). Upward vertical velocities in the tropical lower stratosphere maximize during Northern Hemisphere winter (Rosenlof 1995), and thus the annual cycle in temperatures near the tropical tropopause is commonly attributed to the annual cycle in upwelling in the same region.

A longstanding view is that the long-term mean and annual cycle in upwelling near the tropical tropopause is driven primarily by the momentum deposition from planetary wave breaking in the extratropical stratosphere (Yulaeva et al. 1994; Holton et al. 1995; Ueyama and Wallace 2010; Zhou et al. 2012). However, a number of studies have argued that wave forcing in the tropics and subtropics is necessary to explain the long-term mean observed tropical upwelling (Plumb and Eluszkiewicz 1999; Chen and Sun 2011; Zhou et al. 2012). Recent evidence has suggested that the upwelling in the lowermost tropical stratosphere is strongly determined by shallow meridional overturning circulations driven by local momentum deposition near the tropical and subtropical tropopause (Randel et al. 2008; Birner and Bönisch 2011; Garny et al. 2011; Ueyama et al. 2013). In this view, the forcing for the upwelling (and thus the temperatures) near the tropical tropopause arises largely from 1) extratropical planetary or synoptic-scale waves propagating equatorward and breaking in the subtropical upper troposphere-lower stratosphere (Randel et al. 2008; Garny et al. 2011; Chen and Sun 2011) and/or 2) the equatorial planetary waves depositing westerly momentum in the tropical upper troposphere (Boehm and Lee 2003; Kerr-Munslow and Norton 2006; Norton 2006; Randel et al. 2008; Ryu and Lee 2010; Garny et al. 2011).

The exact roles of extratropical planetary waves, extratropical synoptic-scale waves, and the equatorial planetary waves in governing temperatures in the TTL remain unknown. Most observational studies on this issue have relied on relatively-coarse-vertical-resolution reanalysis and satellite data products (e.g., Ueyama and Wallace 2010; Zhou et al. 2012; Ueyama et al. 2013). But in general, these data are insufficient in capturing finescale vertical temperature structures near the tropical tropopause (e.g., Grise et al. 2010).

The purpose of this study is to exploit the high vertical resolution of GPS radio occultation data to gain new insights into the influence of various wave forcings on the TTL temperature field. The results confirm the strong influence of extratropical stratospheric waves on temperatures throughout the tropical stratosphere but also reveal the unique roles of extratropical tropospheric waves and the equatorial planetary waves in driving temperatures below $20-\mathrm{km}$ altitude. Section 2 describes the data and methods and defines the wave forcings considered in this study. Section 3 examines the signatures of the wave forcings in the TTL temperature field on weekto-week time scales; section 4 examines the signatures of the wave forcings in the TTL temperature field in the longterm mean and annual cycle. Section 5 provides conclusions and a summary of the key results.

\section{Data and methods}

\section{a. Data}

The primary data used in this study are the GPS radio occultation temperature profiles derived from the Constellation Observing System for Meteorology, Ionosphere and Climate (COSMIC) satellite mission (Anthes et al. 2008). The data are freely available from the University Corporation for Atmospheric Research (UCAR)/ COSMIC program and are provided at $100-\mathrm{m}$ vertical resolution from the surface to approximately $40-\mathrm{km}$ altitude. The available data record extends from April 2006 to the present. For this study, we select the four calendar years with the largest number of profiles: 200710. During this period, approximately $1500-2000$ global profiles are available per day, with about $45 \%$ of those profiles lying equatorward of $40^{\circ}$ latitude. We note that the number of COSMIC profiles begins to decay in 2010 and decreases to about 1000 global profiles per day by the end of the year.

The COSMIC mission derives global, high-verticalresolution measurements of atmospheric temperature using the GPS radio occultation technique. The retrieval technique is based upon the refraction of the radio signal emitted by a GPS transmitter satellite as it passes through the limb of Earth's atmosphere (Kursinski et al. 1997). The technique is affected by water vapor, but the biases due to water vapor are very small in regions where temperatures are colder than $250 \mathrm{~K}$ (Kursinski 
TABLE 1. Correlations between the wave forcings defined in section 2c. Correlations that are $95 \%$ significant are listed in boldface. The asterisk indicates that the correlation is 0.49 when $v^{*} T^{*}$ leads $u^{*} v^{*}$ by one pentad.

\begin{tabular}{lccc}
\hline \hline & $\begin{array}{c}100-1000-\mathrm{hPa} u^{*} v^{*} \\
\left(25^{\circ} \text { latitude }\right)\end{array}$ & $\begin{array}{l}100-\mathrm{hPa} v^{*} T^{*} \\
\left(25^{\circ}-90^{\circ} \text { latitude }\right)\end{array}$ & $\begin{array}{c}1-70-\mathrm{hPa} u^{*} v^{*} \\
\left(25^{\circ} \text { latitude }\right)\end{array}$ \\
\hline EPWI & -0.06 & 0.01 & 0.01 \\
$1-70-\mathrm{hPa} u^{*} v^{*}\left(25^{\circ}\right.$ latitude $)$ & $\mathbf{0 . 1 3}$ & $\mathbf{0 . 4 4}$ & \\
$100-\mathrm{hPa} v^{*} T^{*}\left(25^{\circ}-90^{\circ}\right.$ latitude $)$ & -0.03 & & \\
\hline
\end{tabular}

et al. 1997). Here, we focus on the COSMIC data at levels above the upper troposphere where water vapor is known to have little effect on the GPS temperature retrievals.

We supplement the COSMIC temperature profiles with temperatures and winds from the European Centre for Medium-Range Weather Forecasts (ECMWF) Interim Re-Analysis dataset (ERA-Interim; Dee et al. 2011). The reanalysis data are obtained from ECMWF. The reanalysis data record begins in 1979 and assimilates COSMIC data starting in December 2006 (Dee et al. 2011).

\section{b. Methods}

The amplitude of the annual cycle in a time series is measured using a linear regression fit to the annual harmonic:

$$
A \cos (\omega t)+B \sin (\omega t)+C,
$$

where $A$ is the regression coefficient between the time series and $\cos (\omega t), B$ is the regression coefficient between the time series and $\sin (\omega t), C$ is the mean of the time series, and $\omega$ is the angular frequency of the annular harmonic ( $2 \pi / 73$ for pentad data). To remove the seasonal cycle, the first three annual harmonics are subtracted from the COSMIC data.

The statistical significance of the regression coefficient between two time series is estimated by testing whether the associated correlation coefficient is significantly different from zero. The test is performed using the Student's- $t$ statistic applied to the correlation coefficient $r$ with $n^{*}-2$ degrees of freedom:

$$
t=r \sqrt{\frac{n^{*}-2}{1-r^{2}}} .
$$

The effective sample size $n^{*}$ is estimated using the relation

$$
n^{*}=n \frac{1-r_{1} r_{2}}{1+r_{1} r_{2}}
$$

where $n$ is the number of samples and $r_{i}$ is the lag- 1 autocorrelation for the time series $i$ (Bretherton et al. 1999).

\section{c. Wave forcings}

We examine the signatures of four different wave forcings in the TTL temperature field. The four wave forcings are defined as follows.

\section{1) THE EQUATORIAL Planetary WAVES}

The time-varying amplitude of the equatorial planetary waves is estimated using the equatorial planetary wave index (EPWI; Grise and Thompson 2012). The index is calculated using the projection of the anomalous $150-\mathrm{hPa} u^{*}$ field (i.e., the seasonal cycle is removed) onto the seasonally varying climatological-mean $150-\mathrm{hPa}$ $u^{*}$ field over the $20^{\circ} \mathrm{N}-20^{\circ} \mathrm{S}$ domain $\left(u^{*}\right.$ indicates that the zonal mean has been removed from the zonal wind field).

\section{2) WAVES PROPAGATING MERIDIONALLY INTO THE SUBTROPICAL STRATOSPHERE}

The time-varying amplitude of waves propagating meridionally into the subtropical stratosphere is estimated using the poleward eddy momentum fluxes at $25^{\circ}$ latitude vertically averaged over $70-1 \mathrm{hPa}$ in each hemisphere.

\section{3) WAVES PROPAGATING VERTICALLY INTO THE EXTRATROPICAL STRATOSPHERE}

The time-varying amplitude of waves propagating vertically into the extratropical stratosphere is estimated using the 100-hPa poleward eddy heat fluxes averaged over $25^{\circ}-90^{\circ}$ latitude in each hemisphere. (Virtually identical results are found using an average over $45^{\circ}-$ $90^{\circ}$ latitude.)

The resulting index is significantly correlated with the time series of meridionally propagating stratospheric waves defined in section $2 \mathrm{c}(2)$ above (Table 1); that is, extratropical planetary waves propagate vertically into the stratosphere and often refract equatorward (e.g., Ueyama et al. 2013). Thus, to isolate the role of waves that propagate vertically into the extratropical stratosphere but do not propagate into the subtropical stratosphere, linear regression is used to remove the component of the index that is congruent with variability in the meridionally propagating waves. The removal is performed at two lags (lag 0 and lag +1 pentad) 
to account for any time lag between the vertical and meridional propagation of the waves (see correlations in Table 1). The resulting time series is uncorrelated with the time series of the meridionally propagating waves at both lag 0 and lag +1 pentad.

\section{4) WAVES PROPAGATING MERIDIONALLY INTO THE SUBTROPICAL TROPOSPHERE}

The time-varying amplitude of waves propagating meridionally into the subtropical troposphere is estimated using the poleward eddy momentum fluxes at $25^{\circ}$ latitude vertically averaged over $1000-100 \mathrm{hPa}$ in each hemisphere.

The eddy momentum flux is defined as $u^{*} v^{*}$, where $u$ is the zonal wind, $v$ is the meridional wind, and the asterisks represent deviations from the zonal mean. The eddy heat flux is defined as $v^{*} T^{*}$, where $T$ is the temperature. Both the eddy heat flux and eddy momentum flux are calculated using 6-hourly ERA-Interim data and then averaged to form daily means. Averages of the eddy fluxes across both hemispheres are computed with the Southern Hemisphere fluxes inverted (i.e., multiplied by -1$)$.

\section{Observed signatures of equatorial and extratropical wave forcings}

In this section, we examine the signatures in highvertical-resolution temperature data of the four wave forcings outlined in section 2c: the equatorial planetary waves, waves propagating meridionally into the subtropical stratosphere, waves propagating vertically into the extratropical stratosphere, and waves propagating meridionally into the subtropical troposphere. To do this, we create time series of the four wave forcings (see section $2 \mathrm{c}$ for details), remove the mean seasonal cycle, and regress pentad-mean COSMIC temperature anomalies onto standardized values of each time series. The results are thus indicative of the signatures of the wave forcings on week-to-week time scales. The signatures of the wave forcings in the long-term mean and annual cycle are discussed in section 4 .

The results in this section are based on $4 \mathrm{yr}$ of COSMIC data but are qualitatively similar to results derived from longer periods of reanalysis data (see appendix and Fig. A1). Note that the quasi-biennial oscillation (QBO) was removed from the COSMIC temperature anomalies used in this section. The QBO was removed using linear regression fits to the first two principal component time series of the equatorial zonal wind over the $10-70-\mathrm{hPa}$ domain (Wallace et al. 1993). The removal of the QBO has little influence on the signatures of the wave forcings below $20-\mathrm{km}$ altitude but clarifies the signatures of the wave forcings in the tropical midstratosphere.

\section{a. Equatorial planetary waves}

The top panels in Figs. 1 and 2 show results for the equatorial planetary waves. Figure 1 (top) shows pentad-mean, zonal-mean temperature tendencies $\partial T / \partial t$ regressed onto the EPWI time series as a function of latitude and height, and Fig. 2 (top) shows pentad-mean temperatures (averaged over $10^{\circ} \mathrm{N}-10^{\circ} \mathrm{S}$ ) regressed onto the EPWI time series as a function of lag and height. Because the time series of the wave forcings are standardized, the patterns in the top panels of Figs. 1 and 2 correspond to the anomalies associated with a one standard deviation fluctuation in the amplitude of the equatorial planetary waves. The sign of the results is such that positive values correspond to an enhancement in the amplitude of the climatological-mean pattern of the equatorial planetary waves, and vice versa.

The results in Fig. 1 (top) are analogous to those shown in Fig. 4 of Grise and Thompson (2012) based on reanalysis data, but highlight several finescale structures near the tropical tropopause that are only apparent in the high-vertical-resolution COSMIC data. The results reveal that variability in the equatorial planetary waves is associated with 1) significant zonal-mean cooling equatorward of $10^{\circ}$ latitude near the $17-\mathrm{km}$ level and 2) off-equatorial zonal-mean warming between $10^{\circ}$ and $30^{\circ}$ latitude in both hemispheres at the $15-\mathrm{km}$ level. The negative temperature anomalies associated with the equatorial cooling near $17 \mathrm{~km}$ peak 5 days after the wave forcing and persist near the tropical tropopause for approximately 1 month (Fig. 2, top).

Figure 2 (top) reveals that variability in the equatorial planetary waves is also linked to large variability in tropical tropospheric temperatures. Enhanced amplitude in the equatorial planetary waves is associated with significant negative tropical tropospheric temperature anomalies that are most pronounced 20-30 days before and after peak amplitude in the equatorial planetary waves. The negative tropospheric temperature anomalies are consistent with the relationships between the El Niño-Southern Oscillation (ENSO), the MaddenJulian oscillation (MJO), and the EPWI time series (Grise and Thompson 2012). Significant negative tropicalmean tropospheric temperature anomalies are observed in association with the cold phase of the ENSO cycle (Yulaeva and Wallace 1994) and with the phases of the MJO preceding enhanced convection over the Indian Ocean (Bantzer and Wallace 1996). Thus, the temperature anomalies in Fig. 2 (top) resemble those associated with the observed enhancement in the amplitude of the equatorial planetary waves 1) during the 


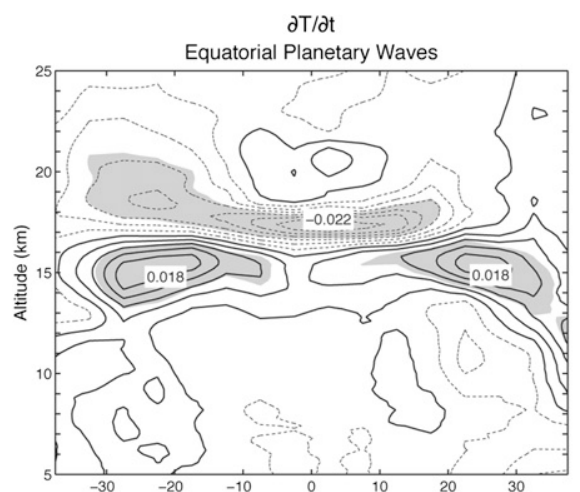

Waves Propagating Meridionally into Subtropical Stratosphere

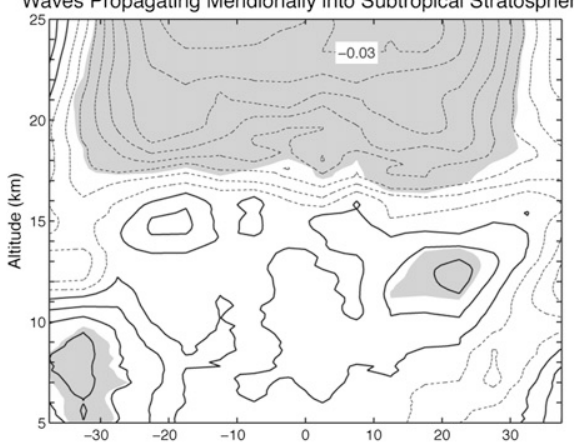

Waves Propagating Vertically into Extratropical Stratosphere

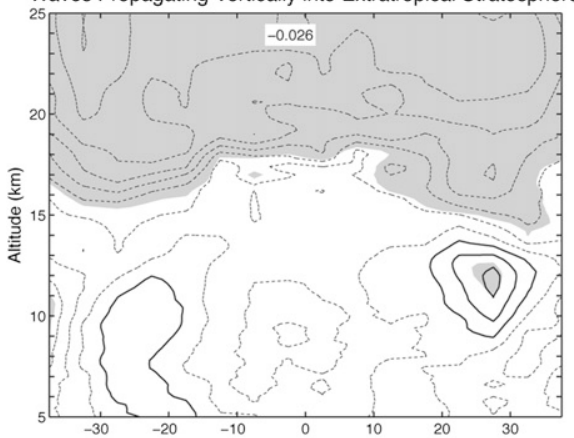

Waves Propagating Meridionally into Subtropical Troposphere

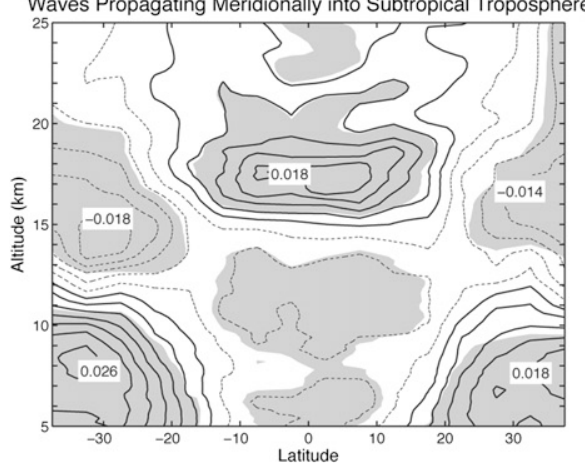

FIG. 1. Regressions of pentad-mean, zonal-mean COSMIC temperature tendency $(\partial T / \partial t)$ anomalies on four wave-forcingindex time series (see section 2c). Positive contours are solid and negative contours are dashed. The contour interval is $4.0 \times 10^{-3} \mathrm{~K} \mathrm{day}^{-1}\left(-6.0 \times 10^{-3},-2.0 \times 10^{-3}, 2.0 \times 10^{-3}, 6.0 \times\right.$ $\left.10^{-3}, \ldots \mathrm{K} \mathrm{day}{ }^{-1}\right)$. Units are per standard deviation in each time series. The shading indicates regions that are $95 \%$ significant. Unless otherwise noted, all figures in this paper are based upon the period 2007-10.
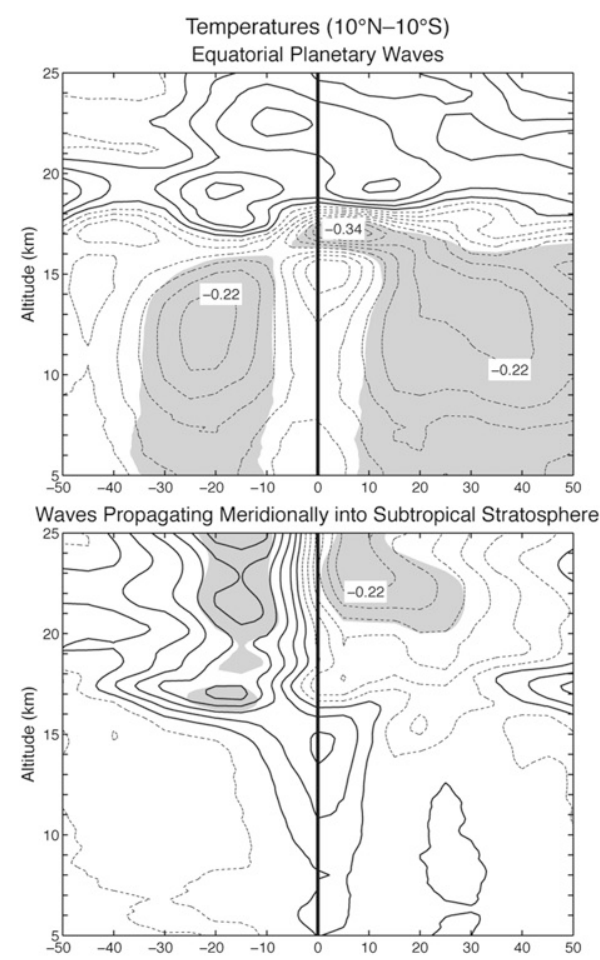

Waves Propagating Vertically into Extratropical Stratosphere

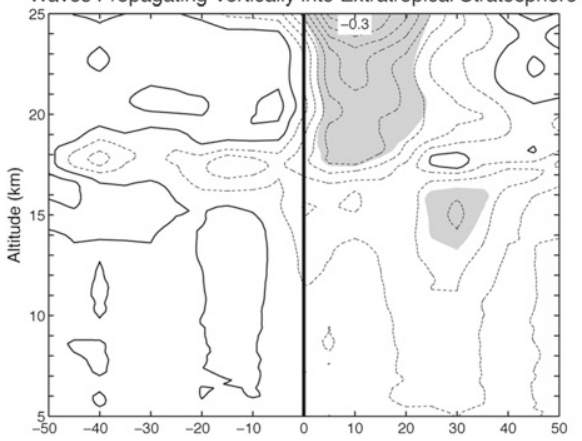

Waves Propagating Meridionally into Subtropical Troposphere

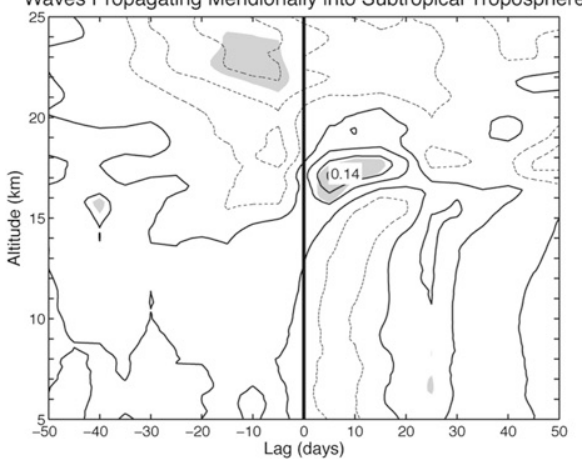

FIG. 2. As in Fig. 1, but for lag regressions of pentad-mean COSMIC temperature anomalies (averaged over $10^{\circ} \mathrm{N}-10^{\circ} \mathrm{S}$ ) on each index time series. Each index time series leads (lags) the temperature anomalies at positive (negative) lags. The contour interval is $0.04 \mathrm{~K}(-0.06,-0.02,0.02,0.06, \ldots \mathrm{K})$. The solid vertical lines denote lag zero. 
cold phase of the ENSO cycle (Dima and Wallace 2007; Grise and Thompson 2012) and 2) during the phases of the MJO with enhanced convection over the western tropical Pacific Ocean (Grise and Thompson 2012; i.e., 20-30 days out of phase from the phases of the MJO associated with negative tropical-mean tropospheric temperature anomalies). Because the linkages between the equatorial planetary waves and tropical-mean tropospheric temperatures are well documented in previous studies, we focus here on the relationship between the equatorial planetary waves and temperatures in the TTL.

Figure 3 provides additional insight into the signature of the equatorial planetary waves in TTL temperatures. The two columns of Fig. 3 show regressions of pentadmean COSMIC temperature anomalies at $15 \mathrm{~km}$ (left column) and $17 \mathrm{~km}$ (right column) onto standardized values of the EPWI time series as a function of lag. Positive tendencies in zonal-mean temperatures at $15 \mathrm{~km}$ (Fig. 1, top) derive primarily from increasing temperatures in the off-equatorial cyclones over the eastern Pacific and Atlantic Oceans (Fig. 3, left column). Negative tendencies in zonal-mean temperatures at $17 \mathrm{~km}$ (Fig. 1, top) derive primarily from a band of negative temperature anomalies stretching eastward from South America along the equator (Fig. 3, right column). The anomalous equatorial cooling near South America propagates eastward following the peak in the EPWI time series (lag 0; Fig. 3, fourth row) and appears to make a near-global circuit in about 25 days. The cooling has a period reminiscent of observed vertically propagating Kelvin waves near the tropical tropopause (Wallace and Kousky 1968; Randel and Wu 2005) and a horizontal structure reminiscent of the Kelvin wavelike response to a transient atmospheric heat source (Heckley and Gill 1984; Hendon and Salby 1994; Bantzer and Wallace 1996).

Figures 1-3 reveal that variability in the equatorial planetary waves is associated not only with pulsation in the amplitude of the climatological-mean pattern of the equatorial planetary waves, but also with a free Kelvin wave-type structure near the tropical tropopause. The Kelvin wave-type structure is a key contributor to zonal-mean tropical temperature anomalies within a shallow layer centered near $17 \mathrm{~km}$. Previous studies have shown that the temperature amplitudes associated with vertically propagating Kelvin and gravity waves do indeed maximize near the $17-\mathrm{km}$ level (e.g., Randel and Wu 2005).

\section{b. Extratropical waves}

The bottom three panels in Figs. 1 and 2 show the regressions of pentad-mean COSMIC $\partial T / \partial t$ (Fig. 1) and temperature (Fig. 2) anomalies onto standardized values of the three extratropical wave indices. The second panels in Figs. 1 and 2 show results for waves propagating meridionally into the subtropical stratosphere. The regression patterns depict broad cooling throughout a deep layer of the tropical stratosphere with amplitudes increasing with height above the tropical tropopause. The temperature anomalies in the midstratosphere are largest 5-10 days following the peak in the wave forcing, and the temperature anomalies in the lowermost stratosphere persist for 1-2 months (Fig. 2, second panel), consistent with the long radiative time scales there. The structure of the tropical stratospheric temperature anomalies is independent of the hemisphere of the wave forcing, but the amplitude of the tropical temperature anomalies is largest when both hemispheres are considered together (Fig. 4, top). Concurrent wave forcing of the same sign in both hemispheres is capable of driving a larger tropical temperature signal than forcing from a single hemisphere alone.

The third panels in Figs. 1 and 2 show results for waves propagating vertically into the extratropical stratosphere. Recall that the index used here describes waves that 1) propagate vertically into the stratosphere but 2) do not propagate to subtropical latitudes (i.e., the waves break in the extratropical stratosphere). The temperature anomalies associated with the vertically propagating waves are comparable in amplitude and structure to those associated with waves propagating meridionally into the subtropical stratosphere with two notable exceptions: waves that propagate into the subtropical stratosphere 1) influence a narrower meridional region (cf. second and third panels in Fig. 1) and 2) appear to have a more pronounced precursor in the tropical temperature field (cf. second and third panels in Fig. 2). The structure of the tropical stratospheric temperature anomalies associated with the vertically propagating stratospheric waves is again independent of the hemisphere of the wave forcing (Fig. 4, middle).

The bottom panels in Figs. 1 and 2 show results for waves propagating meridionally into the subtropical troposphere. Recall that positive values of the index used here are associated with poleward momentum flux anomalies in the subtropical upper troposphere of both hemispheres. The regions of anomalous cooling centered near $16 \mathrm{~km}$ and warming centered below $10 \mathrm{~km}$ in the subtropics (Fig. 1, bottom) are consistent with the patterns of vertical motion driven by anomalous momentum flux divergence in the subtropical upper troposphere of both hemispheres (not shown). More interestingly, enhanced subtropical momentum flux anomalies are also linked to a region of significant 

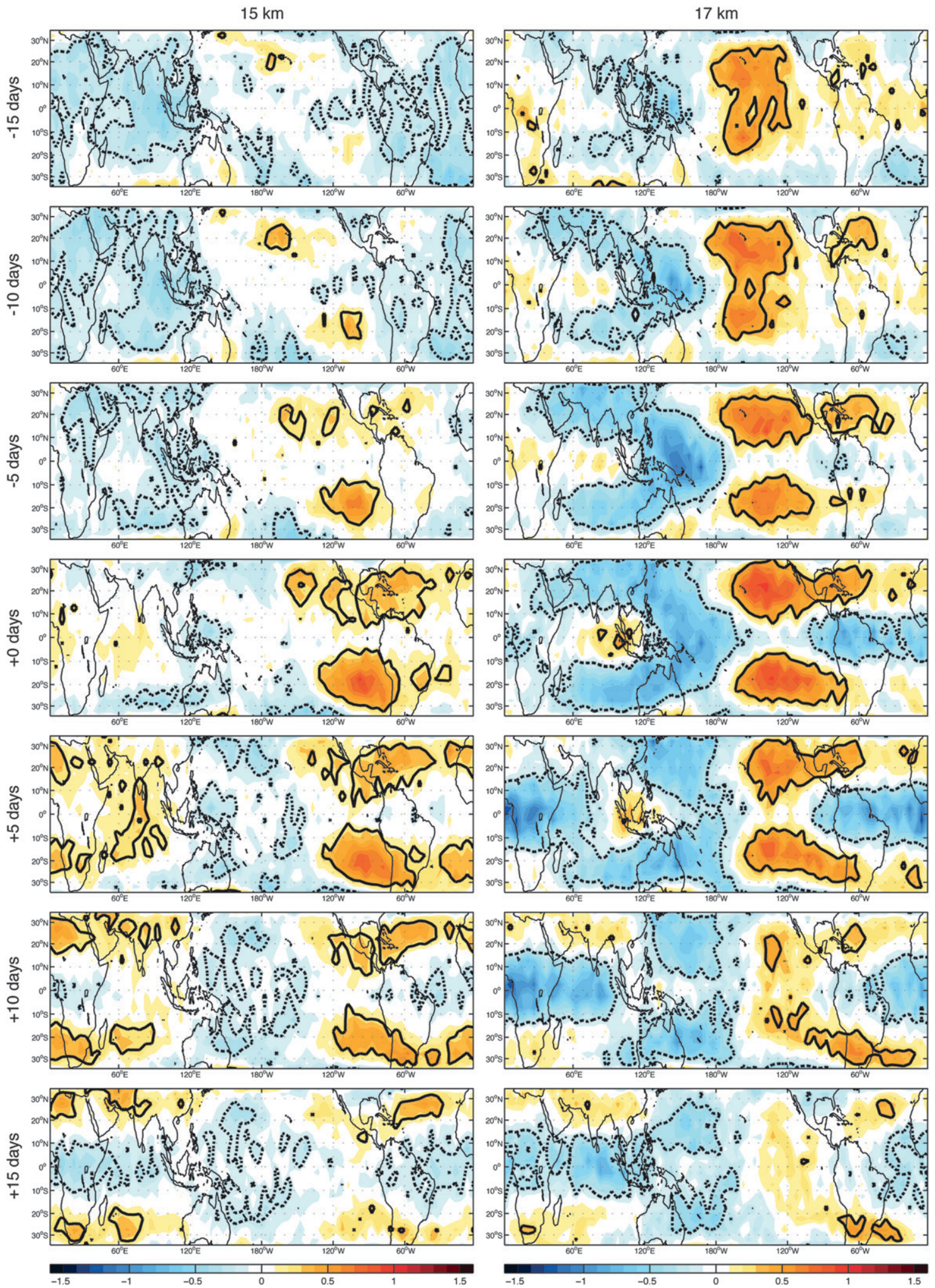

FIG. 3. Lag regressions of pentad-mean COSMIC (left) 15- and (right) 17-km temperature anomalies on the EPWI time series. The EPWI time series leads (lags) the temperature anomalies at positive (negative) lags. The contour interval is $0.1 \mathrm{~K}$. Units are per standard deviation in the EPWI time series. The thick lines outline regions that are $95 \%$ significant. 


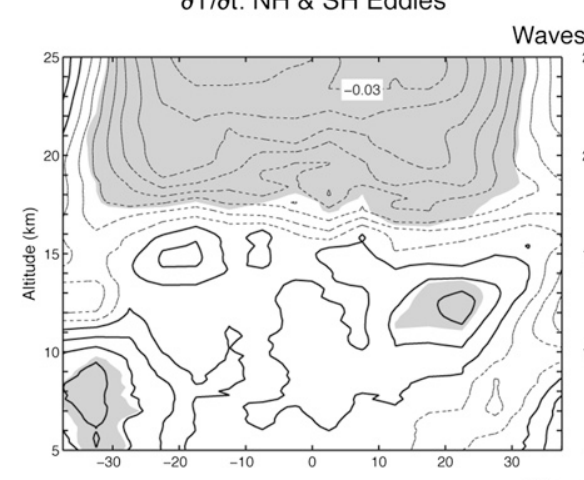

Waves Propagating Meridionally into Subtropical Stratosphere
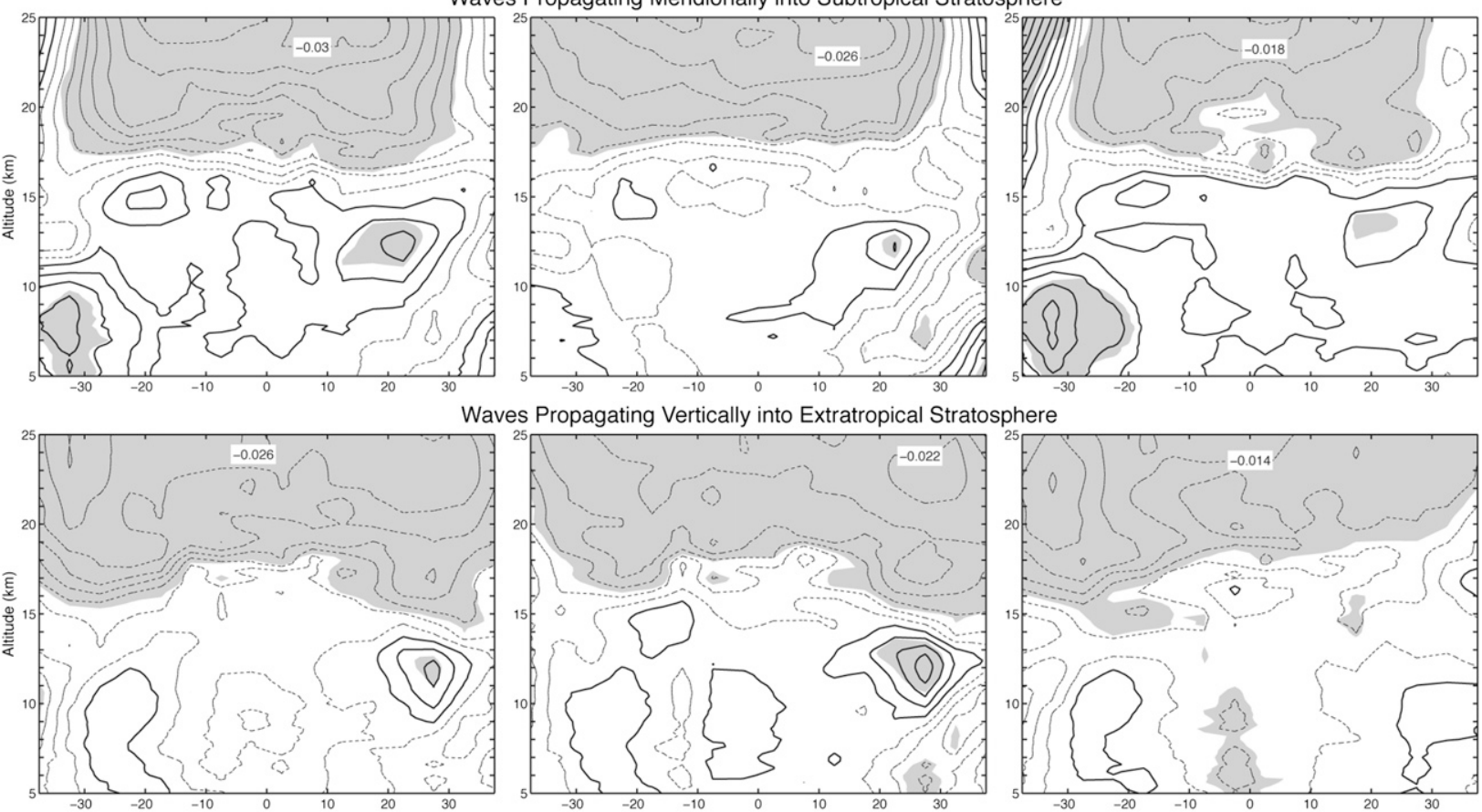

Waves Propagating Meridionally into Subtropical Troposphere
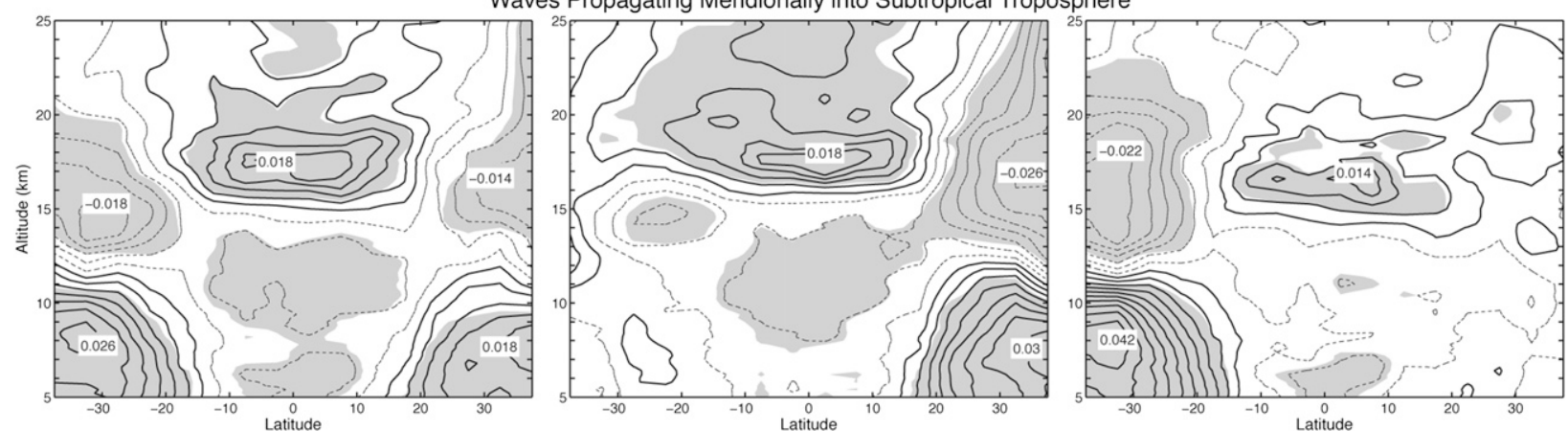

FIG. 4. As in the bottom three rows of Fig. 1, but the COSMIC $\partial T / \partial t$ anomalies are regressed on indices derived from eddies in (left) both hemispheres (as in Fig. 1), (middle) the Northern Hemisphere only, and (right) the Southern Hemisphere only.

warming within a shallow layer near the tropical tropopause. To our knowledge, the existence of this narrow feature in TTL temperatures has not been previously recognized in the literature.

The pattern of TTL temperature anomalies in Fig. 1 (bottom) supports a linkage between subtropical momentum fluxes and upwelling in the TTL, but the polarity of the results is opposite to that expected from previous studies (Randel et al. 2008; see discussion in section $4 \mathrm{~b})$. The subtropical $\partial T / \partial t$ anomalies in Fig. 1 (bottom) are dependent on the hemisphere of the wave forcing, but the shallow layer of warming centered at the equator is linked to subtropical tropospheric wave forcing in both hemispheres (Fig. 4, bottom). The TTL temperature anomalies associated with the subtropical tropospheric wave forcing peak 5-10 days following the wave forcing (Fig. 2, bottom).

\section{c. Summary}

The key results from this section are summarized in Figs. 5 and 6. Figure 5 shows the regressions of pentadmean COSMIC $\partial T / \partial t$ anomalies (averaged over $10^{\circ} \mathrm{N}-$ $10^{\circ} \mathrm{S}$ ) onto the four wave-forcing indices used in this section (i.e., Fig. 5 represents an average of the patterns in Fig. 1 in the deep tropics). Figure 6 shows the regressions of pentad-mean ERA-Interim eddy heat and momentum flux anomalies onto time series of COSMIC $\partial T / \partial t$ anomalies (averaged over $10^{\circ} \mathrm{N}-10^{\circ} \mathrm{S}$ ) at four vertical levels near the tropical tropopause. The polarity of the results is inverted in Fig. 6, such that positive 


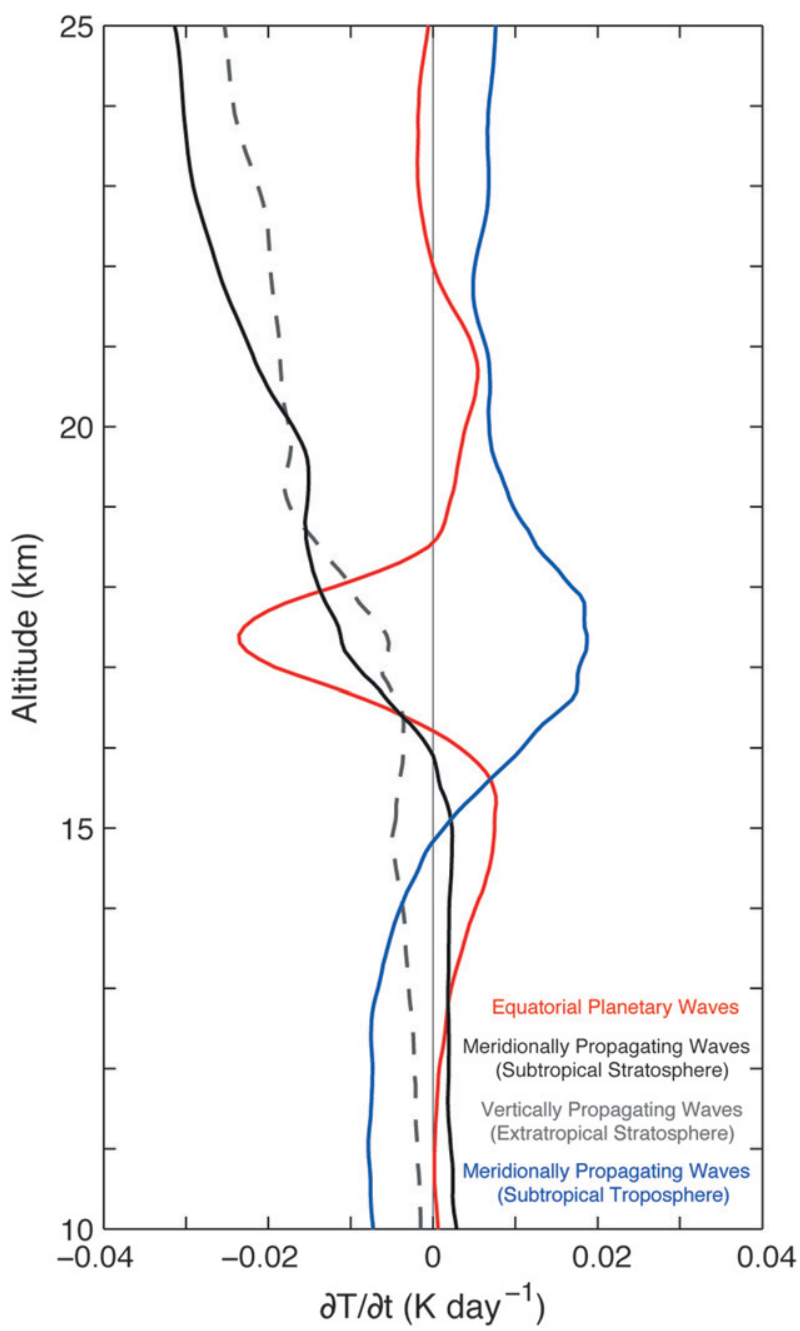

FIG. 5. Regressions of pentad-mean COSMIC $\partial T / \partial t$ anomalies (averaged over $10^{\circ} \mathrm{N}-10^{\circ} \mathrm{S}$ ) on the four wave-forcing-index time series from section $2 \mathrm{c}$. The dashed line represents waves propagating vertically into the extratropical stratosphere.

regression coefficients correspond to cooling near the tropical tropopause.

The vertical signatures of the wave forcings in the tropical temperature field can be summarized as follows:

1) Enhanced stratospheric wave fluxes (poleward eddy heat fluxes in the extratropical stratosphere and poleward eddy momentum fluxes in the subtropical stratosphere) lead to cooling in the tropical stratosphere that increases with height above $16 \mathrm{~km}$ (Fig. 5 , black and dashed gray lines). The increasingly important role of the stratospheric heat fluxes in driving temperatures at progressively higher altitudes is readily apparent in Fig. 6 (left).

2) Increases in poleward subtropical tropospheric momentum fluxes lead to warming in the TTL that peaks between 15.5 and $20 \mathrm{~km}$ (Fig. 5, blue line). Temperature changes at 17.5 and $18.5 \mathrm{~km}$ are strongly linked to momentum fluxes at a lower altitude in the upper troposphere (Fig. 6, right; near $30^{\circ}$ latitude, $300-200 \mathrm{hPa}$ ). Note that while tropospheric momentum fluxes can induce upwelling into the stratosphere on transient time scales, the upwelling cannot be maintained in the steady state (e.g., Haynes et al. 1991).

3) Increased amplitude in the equatorial planetary waves leads to warming near $15 \mathrm{~km}$ and cooling in a very narrow layer between 16 and $18.5 \mathrm{~km}$ (Fig. 5, red line). Increased amplitude in the equatorial planetary waves is marked by the convergence of equatorially symmetric eddy momentum flux anomalies in the tropical upper troposphere near $150 \mathrm{hPa}$ [Fig. 6, right column at $17.5 \mathrm{~km}$; see also Grise and Thompson (2012)].

Hence, stratospheric, subtropical tropospheric, and equatorial planetary wave forcings all have important but very different signatures in TTL temperatures. The temperature response to the equatorial and subtropical tropospheric wave forcings peaks in a narrow $1-2-\mathrm{km}$ layer surrounding the tropical tropopause, whereas the temperature response to the subtropical and extratropical stratospheric wave forcings peaks in the tropical midstratosphere. Consistent with Ueyama et al. (2013), stratospheric wave drag has a relatively weak influence on tropical temperatures below $70 \mathrm{hPa}(\sim 18.5 \mathrm{~km})$.

\section{Signatures in the long-term mean and annual cycle}

In this section, we examine the long-term mean and annual cycle in TTL temperatures. We confirm previous results and provide new insights into the structure of the TTL temperature field using COSMIC data.

\section{a. Long-term mean}

Figure 7 (left) displays the long-term mean COSMIC temperatures at four vertical levels near the tropical tropopause: 11, 14, 17, and $22 \mathrm{~km}$. At $11 \mathrm{~km}$, the tropics are warmer than the subtropics, and the warmest regions occur within a horseshoe-shaped region in the Eastern Hemisphere and a local maximum over South America. The warmest regions are characterized by deep convection and by high geopotential heights associated with the long-term mean pattern of the equatorial planetary waves (Dima et al. 2005; Dima and Wallace 2007). At $17 \mathrm{~km}$, the temperatures are very similar in structure to those at $11 \mathrm{~km}$ but reversed in sign, with the coldest temperatures over the deep tropics. At 14 and $22 \mathrm{~km}$, 

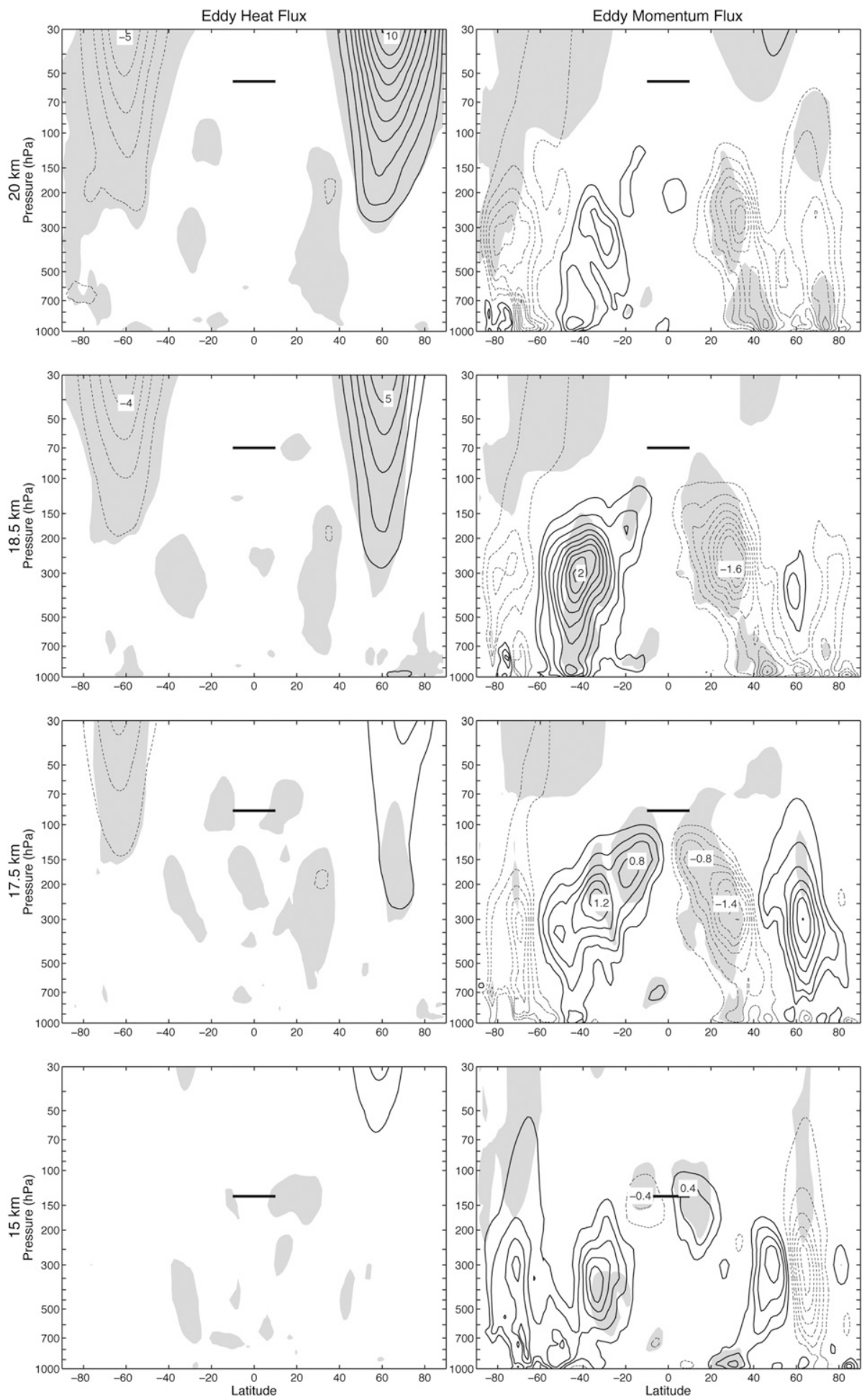

FIG. 6. Regressions of ERA-Interim pentad-mean (left) eddy heat flux and (right) eddy momentum flux anomalies (weighted by density) onto index time series of COSMIC $\partial T / \partial t$ anomalies (averaged over $10^{\circ} \mathrm{N}-10^{\circ} \mathrm{S}$ ) at selected vertical levels (as indicated by the thick horizontal lines). Positive regression coefficients are associated with cooling (i.e., negative $\partial T / \partial t$ ) near the tropical tropopause. Positive contours are solid and negative contours are dashed. The contour interval is (left) $1 \mathrm{~K} \mathrm{~m} \mathrm{~s}^{-1}$ and (right) $0.2 \mathrm{~kg} \mathrm{~m}^{-1} \mathrm{~s}^{-2}$. Units are per standard deviation in each time series. The shading indicates regions that are $95 \%$ significant. 

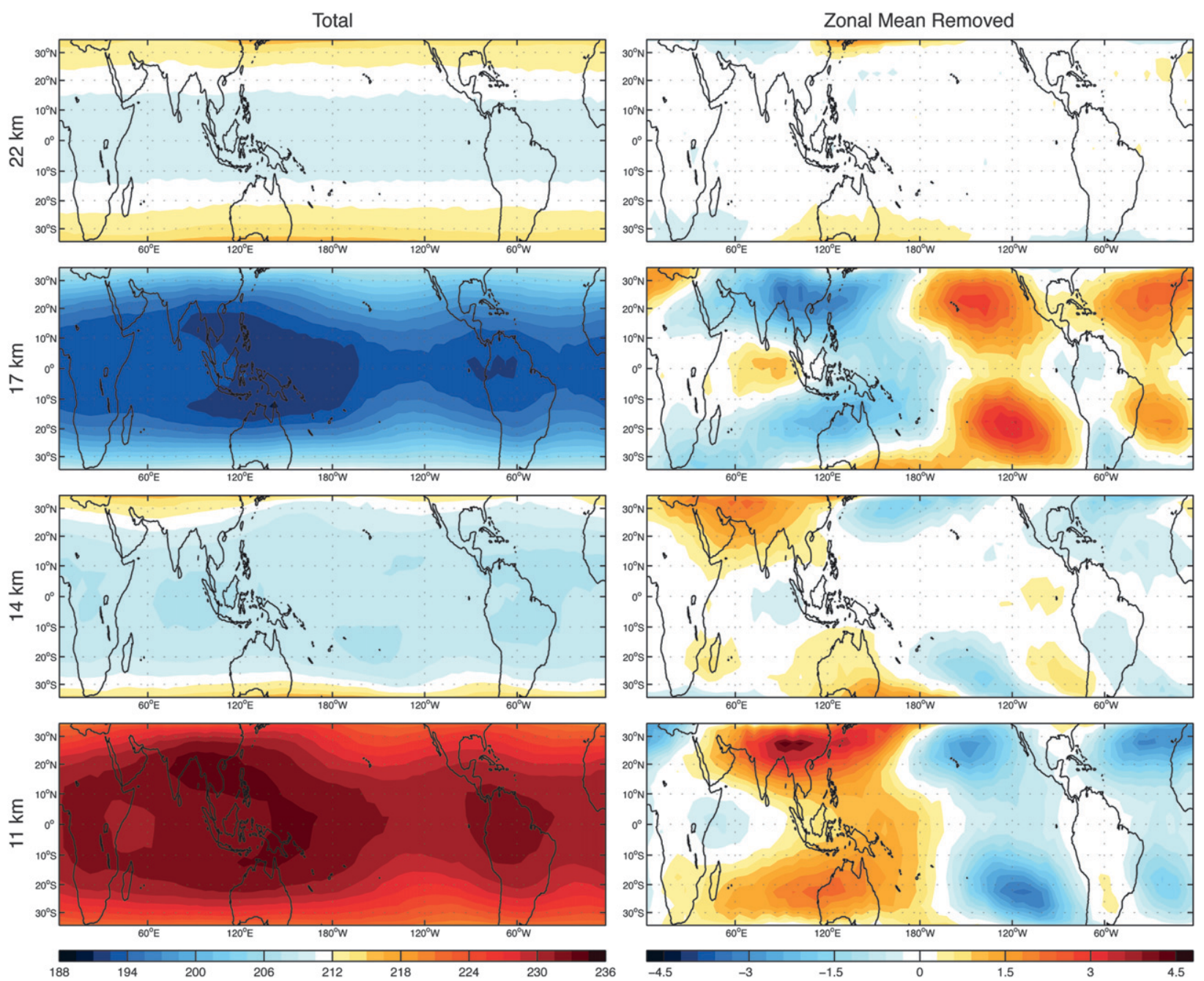

FIG. 7. (left) Long-term mean COSMIC temperatures at selected altitude levels. (right) As in (left), but the zonal mean has been removed. The contour interval is $1.5 \mathrm{~K}$ in the left panels and $0.3 \mathrm{~K}$ in the right panels.

the temperatures are zonally symmetric, and the structures associated with the equatorial planetary waves are virtually absent.

The signature of the equatorial planetary waves in the long-term mean temperature structure is accentuated by removing the zonal mean from the left column of Fig. 7. In the tropics, the temperature field exhibits pronounced zonally asymmetric features at 11 and $17 \mathrm{~km}$ but relatively weak zonally asymmetric features at 14 and $22 \mathrm{~km}$ (Fig. 7, right). The zonally asymmetric temperature structures at 11 and $17 \mathrm{~km}$ strongly resemble the long-term mean pattern of the equatorial planetary waves, with paired off-equatorial anticyclones over the western Pacific Ocean and paired off-equatorial cyclones over the eastern Pacific and Atlantic Oceans (e.g., Dima and Wallace 2007; Grise and Thompson 2012). The temperature structures at the two levels are reversed in sign because the maximum amplitude of the equatorial planetary waves occurs between the levels near $14 \mathrm{~km}$ (Dima and Wallace 2007).

The vertical structure of the amplitude of the wave component of the tropical temperature field is shown in Fig. 8. Figure 8 (left) shows the spatial standard deviation of the zonally asymmetric component of the long-term mean temperature field $T^{*}$ over the domain $30^{\circ} \mathrm{N}-30^{\circ} \mathrm{S}\left(T^{*}\right.$ indicates that the zonal mean has been removed from the temperature field). Because the $T^{*}$ field is dominated by the equatorial planetary waves in the deep tropics (Fig. 7, right), the spatial standard deviation of the long-term mean provides a simple measure of the amplitude of the equatorial planetary waves in the climatological mean as a function of height (cf. Fig. 7 of Dima and Wallace 2007). The results in Fig. 8 (left) depict two layers of large zonal asymmetries in the 

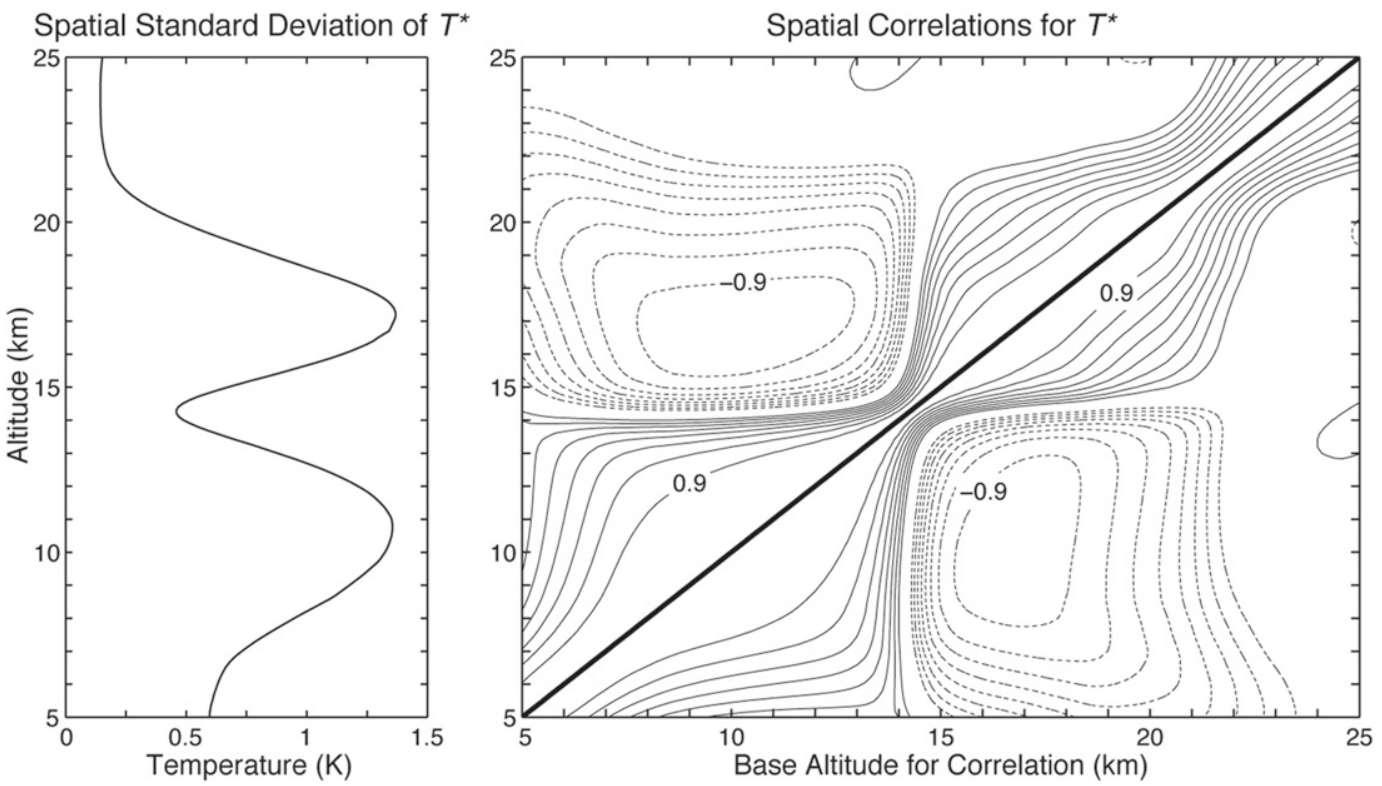

FIG. 8. (left) Spatial standard deviation of the $T^{*}$ field over the $30^{\circ} \mathrm{N}-30^{\circ} \mathrm{S}$ domain in the COSMIC data. (right) Spatial correlations of the $T^{*}$ field $\left(30^{\circ} \mathrm{N}-30^{\circ} \mathrm{S}\right)$ at a given level (indicated on the abscissa) with the $T^{*}$ field $\left(30^{\circ} \mathrm{N}-\right.$ $30^{\circ} \mathrm{S}$ ) at all vertical levels in the COSMIC data. The thick diagonal line signifies a correlation of 1.0.

temperature field of the tropical atmosphere: one centered at $11 \mathrm{~km}$ (Fig. 7, bottom) and one centered at $17 \mathrm{~km}$ (Fig. 7, second row). The amplitude of the wave component of the tropical temperature field exhibits a pronounced minimum near $14 \mathrm{~km}$ (Fig. 7, third row).

Figure 8 (right) shows the spatial cross correlations of the $T^{*}$ field for all vertical levels between 5- and $25-\mathrm{km}$ altitude (over the $30^{\circ} \mathrm{N}-30^{\circ} \mathrm{S}$ domain). By construction, the spatial correlation coefficients are equal to 1.0 along the solid diagonal line in Fig. 8 (right). The zonally asymmetric component of the long-term mean temperature field is vertically coherent within the layers extending from 5 to $14 \mathrm{~km}$ and 14 to $21 \mathrm{~km}$ but out of phase between these two regions. The large negative correlations in the figure confirm that the peaks in the amplitude of the wave component of the tropical temperature field near 11 and $17 \mathrm{~km}$ arise from the same pattern but with opposite polarity in the two layers.

The results in this section are consistent with those of previous studies based on reanalysis data (Dima and Wallace 2007; Fueglistaler et al. 2009), but the results shown in Figs. 7 and 8 suggest that the long-term mean tropical temperature field can be divided into four distinct regions:

1) $\sim 5-13.5 \mathrm{~km}$ : The tropical temperature field is marked by large wavelike features that resemble the equatorial planetary waves.
2) $\sim 13.5-15 \mathrm{~km}$ : The tropical temperature field has weak wave amplitude.

3) $\sim 15-20 \mathrm{~km}$ : The tropical temperature field is marked by large wavelike features that resemble the equatorial planetary waves.

4) Above $\sim 20 \mathrm{~km}$ : The tropical temperature field has weak wave amplitude.

Layers 1 and 3 correspond to the middle-baroclinic and capping layers described by Dima and Wallace (2007), whereas layer 2 corresponds roughly to the base of the tropical tropopause layer defined by Fueglistaler et al. (2009). However, the COSMIC data allow for a sharper, more definitive picture of the vertical structure of the TTL temperature field (Fig. 8) than that shown in previous studies. For example, the upper influence of the equatorial planetary waves noted here is somewhat higher than that discussed by Dima and Wallace (2007) and Fueglistaler et al. (2009).

The results in this section identify vertical levels where the equatorial planetary waves strongly influence the zonally asymmetric component of the long-term mean temperature field. But the analysis methods used here cannot specify the zonal-mean influence of the equatorial planetary waves on the long-term mean temperature field. The results in section 3 suggest that momentum flux anomalies associated with the equatorial planetary waves can drive zonal-mean temperature changes in the $13.5-15-\mathrm{km}$ layer (Fig. 1, top), even though zonal asymmetries in 

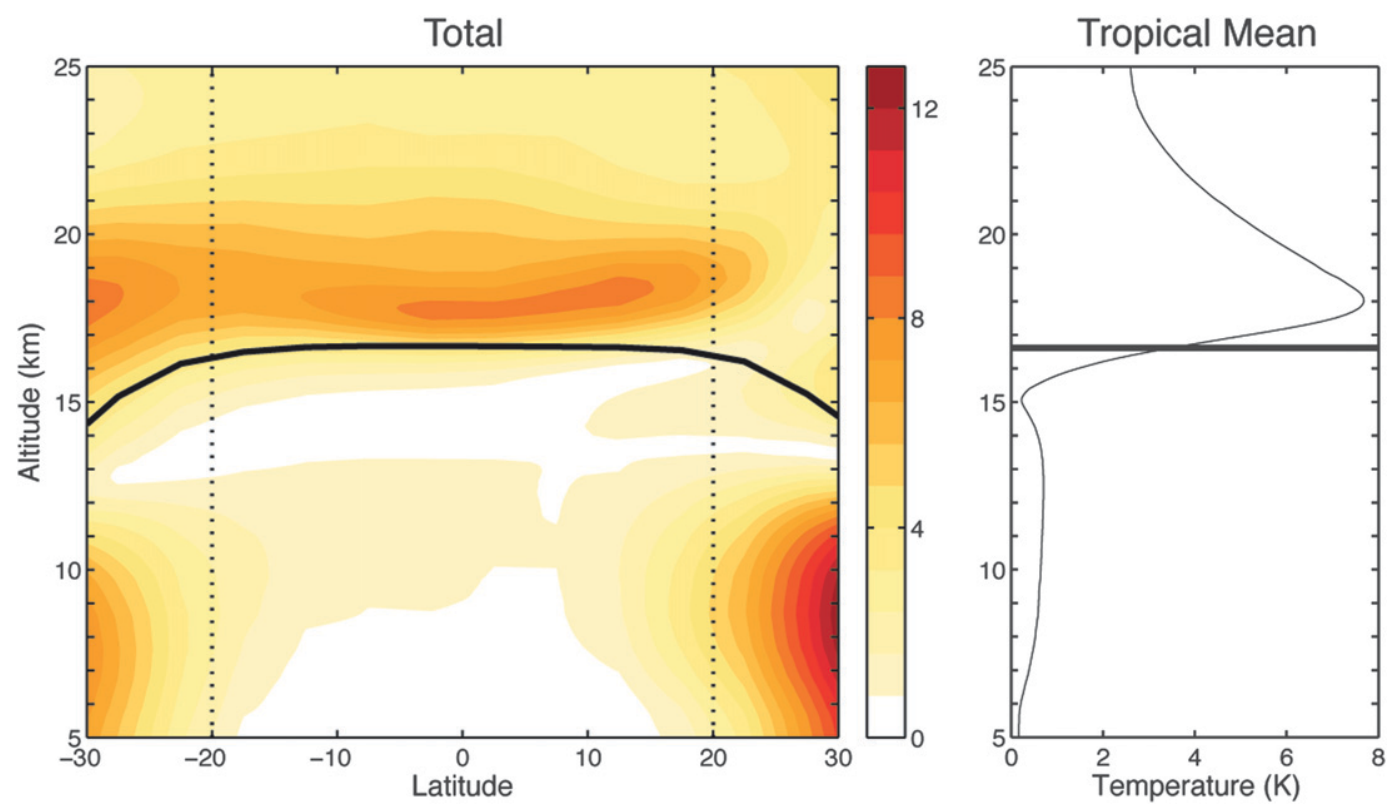

FIG. 9. Amplitude of the annual cycle in COSMIC zonal-mean temperatures: (left) total and (right) tropical-mean (defined from $20^{\circ} \mathrm{N}-20^{\circ} \mathrm{S}$ ). The thick solid black line represents the annual-mean, zonal-mean thermal tropopause height. The contour interval in the left panel is $0.8 \mathrm{~K}$.

the temperature field are relatively weak there (Fig. 3, left).

\section{b. Annual cycle}

Figure 9 (left) shows the amplitude of the annual cycle in zonal-mean temperatures in the COSMIC data. Equatorward of about $20^{\circ}$ latitude, the vertical structure of the annual cycle is consistent with seasonally varying upwelling in the tropical lower stratosphere acting on a mean vertical gradient in radiative time scales (Randel et al. 2002). The largest amplitudes in the annual cycle are found in the 3-4-km-deep layer immediately above the lapse-rate tropopause, where the amplitudes peak at roughly $8 \mathrm{~K}$ near $18 \mathrm{~km}$ (Fig. 9, right; see also Randel et al. 2003; Fueglistaler et al. 2009). Overall, the results in Fig. 9 compare well with those from previous studies conducted with GPS radio occultation data (Randel et al. 2003) and reanalysis data (Fueglistaler et al. 2009).

Figure 10 compares the annual cycle in $17-\mathrm{km}$ tropicalmean temperatures (Fig. 10a) with the annual cycles in the four equatorial and extratropical wave forcings (Figs. 10b-e). The seasonally varying amplitudes of the three extratropical wave forcings are estimated using the indices defined in section 2c. The EPWI time series described in section $2 \mathrm{c}$ cannot be used to estimate the annual cycle in the equatorial planetary waves because it is defined with respect to the seasonally varying structure of the waves. For this reason, the seasonally varying amplitude of the equatorial planetary waves is estimated here from the spatial standard deviation of the $150-\mathrm{hPa}$ $u^{*}$ field.

Note that the inferences drawn from Fig. 10 are based on limited degrees of freedom. That is, the anomaly regressions in section 3 are based on at least $\sim 30$ degrees of freedom, whereas we have only four realizations of the annual cycle. Thus, the quantitative role of each wave forcing in the annual cycle cannot be estimated from linear regression but rather only from diagnostics of the dynamical response to each wave forcing [e.g., as per Randel et al. (2008)], which are beyond the scope of this analysis.

As noted in numerous studies (e.g., Yulaeva et al. 1994), temperatures in the tropical lower stratosphere peak during Northern Hemisphere summer and are lowest during Northern Hemisphere winter (Fig. 10a). The annual cycle in tropical lower stratospheric temperatures is out of phase and slightly lags the annual cycle in the stratospheric wave forcings (Figs. 10c and 10d). The January-March minimum in temperatures near the tropical tropopause is also coincident with similarly timed maxima in 1) the equatorial planetary waves (Fig. 10b) and 2) subtropical wave forcing at tropospheric levels (Fig. 10e). Thus, the annual cycle in temperatures near the tropical tropopause is consistent with driving not only by planetary wave breaking in the extratropical stratosphere (e.g., Yulaeva et al. 1994; Ueyama and Wallace 2010) but also by wave breaking associated with the equatorial planetary waves 


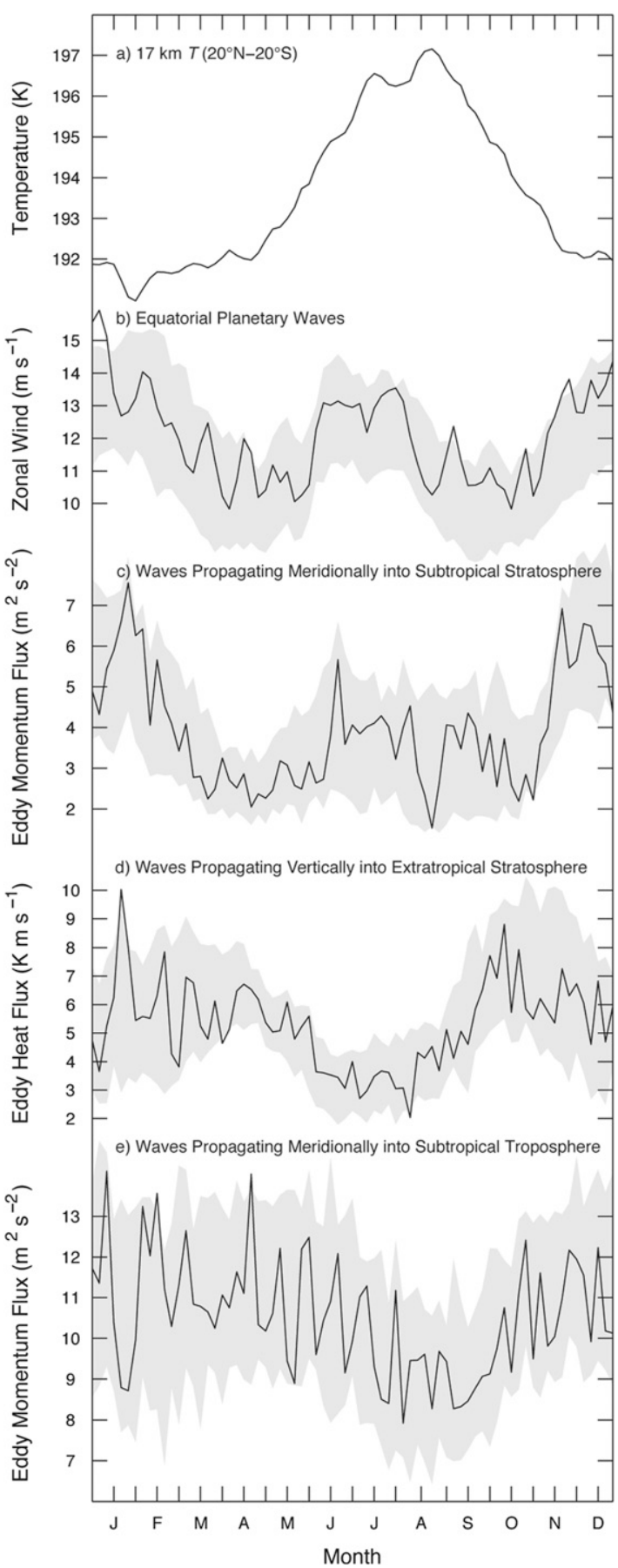

FIG. 10. Time series of the mean annual cycle in the indicated time series. (a) The temperature is calculated using COSMIC data. The wave-forcing time series are defined (b) using the spatial standard deviation of the $150-\mathrm{hPa} u^{*}$ field equatorward of $20^{\circ}$ latitude and (c)-(e) as in section $2 c$ [i.e., variability about the longterm mean in (d) is constrained to be linearly independent of variability about the long-term mean in (c)]. The values in (b)-(e) are calculated using ERA-Interim data; the light gray shading indicates the \pm 1 standard deviation range of the 1979-2010 mean annual cycle.
(Kerr-Munslow and Norton 2006) and subtropical wave forcing in the upper troposphere and lower stratosphere (Randel et al. 2008). However, two additional factors must be considered.

First, the annual cycles in the subtropical stratospheric wave forcing (Fig. 10c) and the equatorial planetary waves (Fig. 10b) both exhibit secondary maxima during June-August that are not mirrored in the annual cycle in temperatures (Fig. 10a). The secondary peak in the subtropical stratospheric wave forcing derives from large poleward momentum fluxes in the Southern Hemisphere subtropical stratosphere during austral winter (not shown). The secondary peak in the equatorial planetary waves is not reproducible in various indices of the waves and is thus not necessarily a robust aspect of the seasonal cycle. Indices based on the uppertropospheric horizontal wind and momentum flux fields possess a secondary maximum during June-August [cf. Fig. 18 of Dima et al. (2005), Fig. 10 of Randel et al. (2008); Fig. 10b], but indices based on the vertical momentum flux field (Kerr-Munslow and Norton 2006; Ueyama and Wallace 2010) or the vertical extent of the waves (Randel et al. 2008) possess only a single maximum during Northern Hemisphere winter [see also discussion in Norton (2006)].

Second, in section 3, we demonstrated that enhanced amplitude in the equatorial planetary waves is associated with cooling in the TTL (Fig. 1, top), while enhanced poleward momentum fluxes in the subtropical upper troposphere are associated with warming in the TTL (Fig. 1, bottom). The results in section 3 are based on intraseasonal time scales. If similar dynamics hold on the time scale of the annual cycle, then the annual cycle in the amplitude of the equatorial planetary waves (Fig. 10b) should drive cooler temperatures in the TTL during Northern Hemisphere winter, whereas the annual cycle in the subtropical tropospheric wave forcing (Fig. 10e) should drive warmer temperatures in the TTL during Northern Hemisphere winter. At first glance, the results contradict previous studies: Randel et al. (2008) and Garny et al. (2011) suggest that both the equatorial planetary waves and the subtropical momentum fluxes due to tropospheric waves contribute to stronger upwelling (and thus enhanced cooling) in the TTL during Northern Hemisphere winter. However, both Randel et al. (2008) and Garny et al. (2011) only consider the component of the equatorial and subtropical wave forcings at and above $100 \mathrm{hPa}$; that is, they do not consider wave fluxes at tropospheric levels. Time series of the subtropical momentum fluxes at tropospheric levels (as used in our study) and lower stratospheric levels [as used in Randel et al. (2008) and Garny et al. (2011)] are not strongly correlated (not shown). 

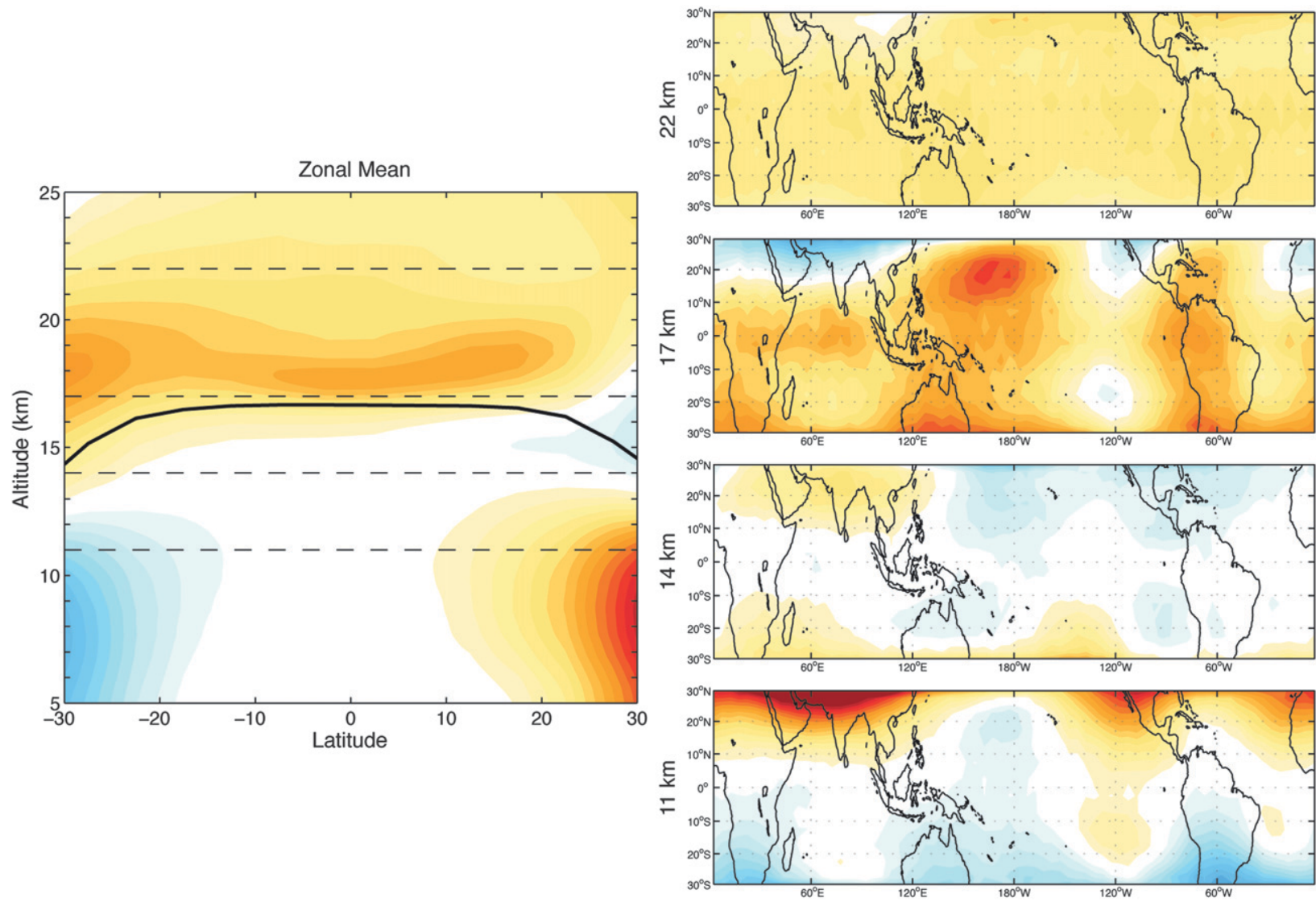

Warmest Temperatures in Jan

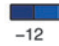

$-8$

1

12

Warmest Temperatures in Jul.

FIG. 11. Amplitude and timing of the annual cycle in COSMIC temperatures: (left) zonal mean and (right) selected vertical levels. The amplitudes reflect a linear regression fit of the temperatures to an annual harmonic with maximum values on 15 July. Positive amplitudes signify an annual cycle with maximum temperatures between $15 \mathrm{Apr}$ and $15 \mathrm{Oct}$, and negative amplitudes signify an annual cycle with maximum temperatures between 15 October and 15 April. The thick solid black line in the left panel represents the annual-mean, zonalmean thermal tropopause height. The contour interval is $0.8 \mathrm{~K}$.

The signature of the equatorial planetary waves in the annual cycle of tropical temperatures is explored further in Fig. 11. Figure 11 (left) is a reproduction of the results from the left panel of Fig. 9, but with the COSMIC temperatures fit to an annual harmonic that peaks on 15 July. Figure 11 (right) shows the corresponding fits to the annual cycle at the levels highlighted in Fig. 7. Warm colors denote peak values during Northern Hemisphere summer (15 July); cool colors denote peak values during Northern Hemisphere winter (15 January).

The annual cycle in tropical temperatures possesses considerable structure not only as a function of height (Fig. 9, left; Fig. 11, left) but also as a function of latitude and longitude (Fig. 11, right). The horizontal asymmetries in the annual cycle strongly resemble the structure of the long-term mean temperature field (Fig. 7). Consequently, the annual cycles at 14 and $22 \mathrm{~km}$ are largely zonally symmetric (Fig. 11, top right and third right), whereas the annual cycles at 11 and $17 \mathrm{~km}$ include large zonal asymmetries that resemble the equatorial planetary waves [Fig. 11, second and bottom right; see also Dima and Wallace (2007)]. The annual cycle at $17 \mathrm{~km}$ also has large amplitude over the equatorial Indian Ocean in a region characterized by strong variability in the MJO and convectively coupled Kelvin waves (Wheeler et al. 2000).

\section{Summary}

Temperatures within the tropical tropopause layer (TTL) reflect a complex combination of stratospheric and tropospheric processes. Zonal asymmetries in TTL temperatures are generally attributed to the quasistationary equatorial planetary wave pattern of the tropical troposphere (Highwood and Hoskins 1998; Fueglistaler 
et al. 2009), whereas the pronounced annual cycle in TTL temperatures is generally attributed to the annual cycle in planetary wave breaking in the Northern Hemisphere extratropical stratosphere (Yulaeva et al. 1994; Holton et al. 1995; Ueyama and Wallace 2010; Zhou et al. 2012). Recent studies have, however, questioned this thinking and proposed a greater role for the equatorial planetary waves and subtropical wave breaking in governing the annual cycle in temperatures near the tropical tropopause (e.g., Boehm and Lee 2003; Norton 2006; Randel et al. 2008; Garny et al. 2011; Chen and Sun 2011; Zhou et al. 2012).

In this study, we revisit the role of extratropical and equatorial waves in governing the long-term mean, annual cycle, and variability in temperatures near the tropical tropopause. Previous observational studies have relied on relatively-coarse-vertical-resolution satellite and reanalysis data and were thus limited in their analyses of the TTL (Dima and Wallace 2007; Zhou et al. 2012; Ueyama et al. 2013). Here, we use high-verticalresolution GPS radio occultation temperature profiles to provide new insight into the contributions of various wave forcings to the temperature structure of the TTL.

The equatorial planetary waves dominate the zonally asymmetric temperature structure of the TTL in the long-term mean, in the annual cycle, and in variability on intraseasonal time scales. The zonally asymmetric structures of the equatorial planetary waves are pronounced within the $\sim 5-13.5$ - and $\sim 15-20-\mathrm{km}$ layers and are absent within the $\sim 13.5-15-\mathrm{km}$ layer and in the stratosphere above about $20 \mathrm{~km}$ (Figs. 7, 8, and 11). In the zonal mean, the equatorial planetary waves are associated with large temperature variability within a shallow $\sim 1-\mathrm{km}$ layer near the tropical tropopause (Fig. 1, top; Fig. 5). The linkage between the equatorial planetary waves and the sharp zonal-mean temperature anomalies near the tropical tropopause is supported by three key observations: 1) variability in the equatorial planetary waves is strongly correlated with the MJO (Grise and Thompson 2012), 2) transient atmospheric heating associated with the MJO excites a rapid eastwardpropagating Kelvin wave feature that acts to homogenize deep tropical temperatures (Fig. 3, right; Bantzer and Wallace 1996), and 3) temperature perturbations in vertically propagating Kelvin waves sharply maximize in high-vertical-resolution temperature measurements near the tropical tropopause (e.g., Randel and Wu 2005).

Vertically and meridionally propagating extratropical stratospheric waves are associated with broad temperature anomalies throughout a deep layer of the tropical stratosphere that persist in the lower stratosphere for several months (Figs. 1 and 2, second and third panels). The signatures associated with the waves are not strongly dependent on the meridional propagation of the waves to subtropical latitudes. The similarity in timing of the annual cycles in TTL temperatures and the vertically propagating waves supports their role in driving the annual cycle in TTL temperatures (Fig. 10).

Meridionally propagating waves in the subtropical troposphere (i.e., at and below $100 \mathrm{hPa}$ ) are associated with temperature anomalies confined below $20-\mathrm{km}$ altitude (Fig. 1, bottom). The influence of the subtropical tropospheric wave forcing on the zonal-mean circulation peaks in two locations: 1) near the subtropical tropopause $\left(\sim 30^{\circ}\right.$ latitude) in both hemispheres and 2) within an approximately 3-4-km layer centered about the tropical tropopause between $15^{\circ} \mathrm{S}$ and $15^{\circ} \mathrm{N}$. The region of TTL temperature anomalies associated with subtropical wave forcing is intriguing and has not been recognized in previous studies. The polarity of the TTL temperature anomalies is in apparent contradiction to prior linkages between the annual cycle in subtropical wave forcing and the annual cycle in TTL upwelling (Randel et al. 2008; Garny et al. 2011). However, as noted earlier, the results in Randel et al. (2008) and Garny et al. (2011) are based on subtropical wave forcing at lower-stratospheric levels, whereas the linkages here are based on subtropical wave forcing at uppertropospheric levels. Future studies might investigate the relationships between TTL temperature anomalies and extratropical eddy forcing in more detail at a wider range of altitudes.

The regression analyses used in this study do not isolate the relative importance of dynamic and radiative processes in driving the observed temperature anomalies. The TTL temperature anomalies discussed here are likely forced not only by adiabatic processes, but also by changes in cloud and radiative processes (e.g., Fueglistaler et al. 2009). For example, the Kelvin wavelike temperature structures shown in Fig. 3 (right) strongly resemble similar structures in TTL cirrus associated with the MJO [cf. Fig. 13 of Virts and Wallace (2010)]. Future diagnostic work might focus on quantifying the relative importance of dynamics, clouds, and radiation in driving the TTL temperature response to the various wave forcings considered here.

A key finding of this study is the relative importance of various wave types in driving tropical temperature variability in the $\sim 15-20$-km layer, as summarized in Fig. 5. Temperatures within this layer strongly affect stratosphere-troposphere transport (e.g., Brewer 1949; Mote et al. 1996; Fueglistaler et al. 2009) and cirrus cloud formation (e.g., Jensen et al. 1996; Massie et al. 2002). Simulations of both stratospheric climate and the radiative balance of the tropics are thus dependent on the ability of numerical models to accurately predict 

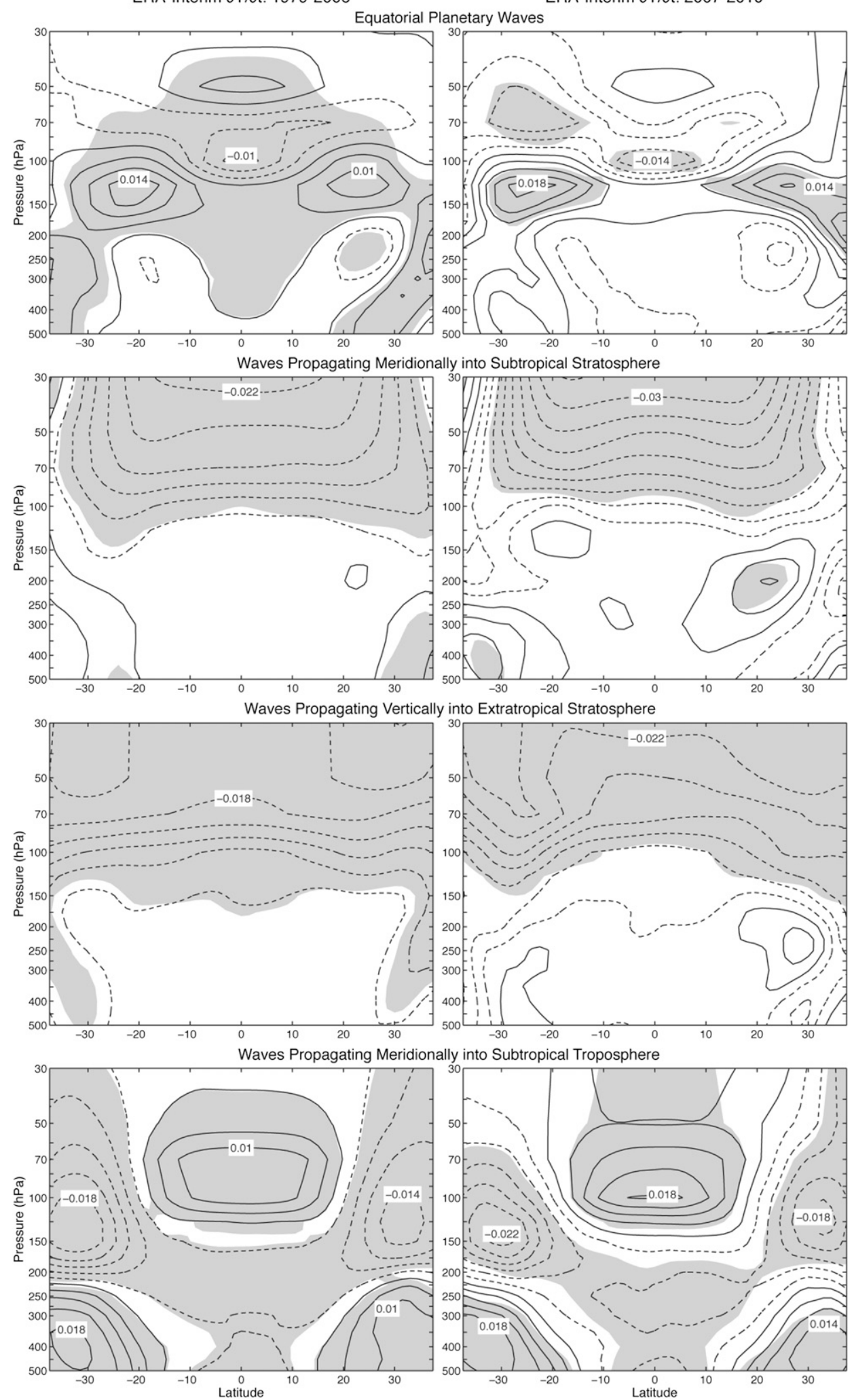

FIG. A1. As in Fig. 1, but for regressions of pentad-mean, zonal-mean ERA-Interim $\partial T / \partial t$ anomalies for the periods (left) 1979-2006 and (right) 2007-10. 
the influence on the TTL of extratropical planetary waves, extratropical synoptic-scale waves, and the equatorial planetary waves.

Acknowledgments. We thank S. Fueglistaler, E. P. Gerber, M. I. Hegglin, P. J. Kushner, S.-W. Son, J. M. Wallace, and two anonymous reviewers for helpful comments during the preparation of this manuscript. We also thank T. Birner for assistance in accessing the COSMIC data. DWJT is funded by the NSF Climate Dynamics program.

\section{APPENDIX}

\section{ERA-Interim Results}

Because the results of this paper rely on only $4 \mathrm{yr}$ of COSMIC data, all analyses were repeated using $32 \mathrm{yr}$ of ERA-Interim temperature data covering the period 1979-2010. By definition, the results have coarser vertical resolution, but they encompass substantially more realizations of the annual cycle and internal variability in the wave indices. In general, the ERA-Interim results are qualitatively similar to those derived from the COSMIC data and strongly support the robustness of the COSMIC results presented in this paper.

Key results from ERA-Interim are shown in Fig. A1. Figure A1 replicates the analysis procedure from Fig. 1 using pentad-mean ERA-Interim temperatures over two independent periods: 1979-2006 (Fig. A1, left) and 2007-10 (Fig. A1, right). The former period is virtually independent of the COSMIC data as the assimilation of COSMIC data into the ERA-Interim began in December 2006 (Dee et al. 2011). The latter period can be used for direct comparison to the COSMIC results presented in Fig. 1. The qualitative signatures from the COSMIC data in Fig. 1 are well replicated in both periods of the reanalysis data.

\section{REFERENCES}

Anthes, R. A., and Coauthors, 2008: The COSMIC/FORMOSAT3 mission: Early results. Bull. Amer. Meteor. Soc., 89, 313-333.

Bantzer, C. H., and J. M. Wallace, 1996: Intraseasonal variability in tropical mean temperature and precipitation and their relation to the tropical 40-50 day oscillation. J. Atmos. Sci., 53, 30323045 .

Birner, T., and H. Bönisch, 2011: Residual circulation trajectories and transit times into the extratropical lowermost stratosphere. Atmos. Chem. Phys., 11, 817-827.

Boehm, M. T., and S. Lee, 2003: The implications of tropical Rossby waves for tropical tropopause cirrus formation and for the equatorial upwelling of the Brewer-Dobson circulation. J. Atmos. Sci., 60, 247-261.

Bretherton, C. S., M. Widmann, V. P. Dymnikov, J. M. Wallace, and I. Bladé, 1999: The effective number of spatial degrees of freedom of a time-varying field. J. Climate, 12, 19902009.

Brewer, A. W., 1949: Evidence for a world circulation provided by the measurements of helium and water vapour distribution in the stratosphere. Quart. J. Roy. Meteor. Soc., 75, 351-363.

Chen, G., and L. Sun, 2011: Mechanisms of the tropical upwelling branch of the Brewer-Dobson circulation: The role of extratropical waves. J. Atmos. Sci., 68, 2878-2892.

Dee, D. P., and Coauthors, 2011: The ERA-Interim reanalysis: Configuration and performance of the data assimilation system. Quart. J. Roy. Meteor. Soc., 137, 553-597.

Dima, I. M., and J. M. Wallace, 2007: Structure of the annual-mean equatorial planetary waves in the ERA-40 reanalyses. J. Atmos. Sci., 64, 2862-2880.

- - - and I. Kraucunas, 2005: Tropical zonal momentum balance in the NCEP reanalyses. J. Atmos. Sci., 62, 2499-2513.

Fueglistaler, S., A. E. Dessler, T. J. Dunkerton, I. Folkins, Q. Fu, and P. W. Mote, 2009:Tropical tropopause layer. Rev. Geophys., 47, RG1004, doi:10.1029/2008RG000267.

Garny, H., M. Dameris, W. Randel, G. E. Bodeker, and R. Deckert, 2011: Dynamically forced increase of tropical upwelling in the lower stratosphere. J. Atmos. Sci., 68, 12141233

Gettelman, A., and P. M. Forster, 2002: A climatology of the tropical tropopause layer. J. Meteor. Soc. Japan, 80, 911-924.

Gill, A. E., 1980: Some simple solutions for heat-induced tropical circulation. Quart. J. Roy. Meteor. Soc., 106, 447-462.

Grise, K. M., and D. W. J. Thompson, 2012: Equatorial planetary waves and their signature in atmospheric variability. J. Atmos. Sci., 69, 857-874.

,-- , and T. Birner, 2010: A global survey of static stability in the stratosphere and upper troposphere. J. Climate, 23, 22752292

Haynes, P. H., C. J. Marks, M. E. McIntyre, T. G. Shepherd, and K. P. Shine, 1991: On the "downward control" of extratropical diabatic circulations by eddy-induced mean zonal forces. J. Atmos. Sci., 48, 651-678.

Heckley, W. A., and A. E. Gill, 1984: Some simple analytical solutions to the problem of forced equatorial long waves. Quart. J. Roy. Meteor. Soc., 110, 203-217.

Hendon, H. H., and M. L. Salby, 1994: The life cycle of the MaddenJulian oscillation. J. Atmos. Sci., 51, 2225-2237.

Highwood, E. J., and B. J. Hoskins, 1998: The tropical tropopause. Quart. J. Roy. Meteor. Soc., 124, 1579-1604.

Holton, J. R., P. H. Haynes, M. E. McIntyre, A. R. Douglass, R. B. Rood, and L. Pfister, 1995: Stratosphere-troposphere exchange. Rev. Geophys., 33, 403-439.

Jensen, E. J., O. B. Toon, H. B. Selkirk, J. D. Spinhirne, and M. R. Schoeberl, 1996: On the formation and persistence of subvisible cirrus clouds near the tropical tropopause. J. Geophys. Res., 101 (D16), 21 361-21 375.

Kerr-Munslow, A. M., and W. A. Norton, 2006: Tropical wave driving of the annual cycle in tropical tropopause temperatures. Part I: ECMWF analyses. J. Atmos. Sci., 63, 1410-1419.

Kursinski, E. R., G. A. Hajj, J. T. Schofield, R. P. Linfield, and K. R. Hardy, 1997: Observing Earth's atmosphere with radio occultation measurements using the Global Positioning System. J. Geophys. Res., 102 (D19), 23 429-23 465.

Massie, S., A. Gettelman, W. Randel, and D. Baumgardner, 2002: Distribution of tropical cirrus in relation to convection. J. Geophys. Res., 107, 4591, doi:10.1029/2001JD001293.

Mote, P. W., and Coauthors, 1996: An atmospheric tape recorder: The imprint of tropical tropopause temperatures 
on stratospheric water vapor. J. Geophys. Res., 101 (D2), 3989-4006.

Norton, W. A., 2006: Tropical wave driving of the annual cycle in tropical tropopause temperatures. Part II: Model results. J. Atmos. Sci., 63, 1420-1431.

Plumb, R. A., and J. Eluszkiewicz, 1999: The Brewer-Dobson circulation: Dynamics of the tropical upwelling. J. Atmos. Sci., 56, 868-890.

Randel, W. J., and F. Wu, 2005: Kelvin wave variability near the equatorial tropopause observed in GPS radio occultation measurements. J. Geophys. Res., 110, D03102, doi:10.1029/ 2004JD005006.

— , R. R. Garcia, and F. Wu, 2002: Time-dependent upwelling in the tropical lower stratosphere estimated from the zonal-mean momentum budget. J. Atmos. Sci., 59, 2141-2152.

, F. Wu, and W. R. Ríos, 2003: Thermal variability of the tropical tropopause region derived from GPS/MET observations. J. Geophys. Res., 108, 4024, doi:10.1029/2002JD002595.

, R. Garcia, and F. Wu, 2008: Dynamical balances and tropical stratospheric upwelling. J. Atmos. Sci., 65, 3584-3595.

Reed, R. J., and C. L. Vlcek, 1969: The annual temperature variation in the lower tropical stratosphere. J. Atmos. Sci., 26, 163-167.

Rosenlof, K. H., 1995: Seasonal cycle of the residual mean meridional circulation in the stratosphere. J. Geophys. Res., 100 (D3), 5173-5191.

Ryu, J.-H., and S. Lee, 2010: Effect of tropical waves on the tropical tropopause transition layer upwelling. J. Atmos. Sci., 67, 31303148.
Ueyama, R., and J. M. Wallace, 2010: To what extent does highlatitude wave forcing drive tropical upwelling in the BrewerDobson circulation? J. Atmos. Sci., 67, 1232-1246.

_, E. P. Gerber, J. M. Wallace, and D. M. W. Frierson, 2013: The role of high-latitude waves in the intraseasonal to seasonal variability of tropical upwelling in the Brewer-Dobson circulation. J. Atmos. Sci., in press.

Virts, K. S., and J. M. Wallace, 2010: Annual, interannual, and intraseasonal variability of tropical tropopause transition layer cirrus. J. Atmos. Sci., 67, 3097-3112.

Wallace, J. M., and V. E. Kousky, 1968: Observational evidence of Kelvin waves in the tropical stratosphere. J. Atmos. Sci., 25, 900-907.

_ _ R. L. Panetta, and J. Estberg, 1993: Representation of the equatorial stratospheric quasi-biennial oscillation in EOF phase space. J. Atmos. Sci., 50, 1751-1762.

Wheeler, M., G. N. Kiladis, and P. J. Webster, 2000: Large-scale dynamical fields associated with convectively coupled equatorial waves. J. Atmos. Sci., 57, 613-640.

Yulaeva, E., and J. M. Wallace, 1994: The signature of ENSO in global temperature and precipitation fields derived from the microwave sounding unit. J. Climate, 7, 1719-1736.

_ J. R. Holton, and J. M. Wallace, 1994: On the cause of the annual cycle in tropical lower-stratospheric temperatures. J. Atmos. Sci., 51, 169-174.

Zhou, T., M. A. Geller, and W. Lin, 2012: An observational study on the latitudes where wave forcing drives Brewer-Dobson upwelling. J. Atmos. Sci., 69, 1916-1935. 